Bartın Üniversitesi

Eğitim Fakültesi Dergisi

Cilt 6, Sayı 1, s.16-28, Şubat 2017

BARTIN - TÜRKIYE

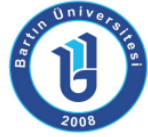

ISSN: 1308-7177
Bartin University

Journal of Faculty of Education

Volume 6, Issue1, p. 16-28, February2017

BARTIN - TURKEY

\title{
Lisansüstü Öğrencilerin Tez Önerisi Hazırlarken Zorlandıkları Kısımların İkili Karşılaştırma Yöntemi ile Ölçeklenmesi
}

Filiz ISNAÇ, Milli Eğitim Bakanlığı, filiz.temel30@gmail.com

C. Deha DOĞAN, Yrd. Doç. Dr., Ankara Üniversitesi, Eğitim Bilimleri Fakültesi, dehadogan@gmail.com

Öz: Bu çalışmanın amacı lisansüstü öğrencilerinin bir tez önerisi hazırlarken hangi bölümlerde daha çok zorlandıklarını ikili karşılaştırma yöntemi ile ölçeklemektir. Çalışma, 2015-2016 Eğitim- Öğretim yılında Ankara Üniversitesi, Hacettepe Üniversitesi ve Mersin Üniversitesi Eğitim Fakültesi'nde öğrenim gören; bir ders kapsamında en az bir tez önerisi yazmış olan bilimsel hazırlık, yüksek lisans ve doktora öğrencileri arasından seçilmiş 102 kişi ile gönüllülük esasına dayalı olarak yürütülmüştür. Örneklemin belirlenmesinde uygun (kolay ulaşılabilir) örnekleme yöntemi kullanılmıştır. Veriler araştırmacılar tarafından hazırlanmış "Tez Önerisi İkili Karşılaştırma Formu” ile toplanmıştır. Toplanan veriler Thurstone'nin Karşılaştırmalı Yargılar Kanunu'nun V. Hal denklemi kullanılarak analiz edilmiştir. Araştırma sonucunda elde edilen bulgulara göre lisansüstü öğrencilerinin tez önerisi yazarken en çok zorluk yaşadığı bölümün problem durumu olduğu görülmüştür. Bunu sırasıyla veriler ve çözümlenmesi, araştırmanın önemi, veriler ve toplanması, araştırma modeli, amaç ve alt amaçlar, evren ve örneklem, varsayımlar ve sınırlılıklar takip etmiştir. Araştırmadan elde edilen bilgilere göre lisansüstü düzeyde verilen araştırma yöntemleri ders içeriklerinin öğrencilerin zorluk yaşadığı boyutlara ağırlık verecek şekilde düzenlenmesi önerilebilir.

Anahtar Sözcükler: ölçekleme, ikili karşılaştırma yöntemi, v. hal denklemi, tez önerisi, lisansüstü öğrenci

\section{Scaling the Sections that Graduate Students Have Difficulty in the Course of Writing Thesis Proposal with Pairwise Comparison Method}

\begin{abstract}
The aim of this study is to scale the parts that graduate students had difficulties whilewriting a thesis proposal based on their judgement with paired comparison method, The study was conducted with 102 graduate students in Ankara, Hacettepe and Mersin University Faculty of Education in 2015-2016 academic year. Conveninent sampling method was used in the study. Data was collected through "Paired Comparison Form" which was prepared by the researchers. The collected data were analyzed using the fifth conditional equation of Thurstone's law of comparative judgement. According to the results of the study, the part which graduate students have the most difficulties while writing thesis proposal is "problem situation". This is followed by "data and analiysis", "importance of the research", "data and collection", "research model", "aims and sub-aims of the study" "universe and samplimng, "hypothesis" and "limitations" parts.It is advised that content of the research methodology courses in graduate levels should be revised according to the parts that the students have more difficulties.
\end{abstract}

Key Words: paired comparison method, scaling, fifth conditional equation, thesis proposal, graduate student 


\section{GiRiş}

Insanoğlunun kendisini ve doğayı anlama çabaları bilimin gelişmesini sağlamıştır. Bilim, bilimsel yöntemi kullanarak bilgi üretme işi olarak tanımlanabilir. Gündelik yaşamda karşılaştığımız problemlere çözüm bulabilmek için deneyimlerimiz, bireysel gözlemlerimiz otorite kabul ettiğimiz kişilerin önerileri gibi çeşitli bilgi kaynaklarından elde ettiğimiz bilgiler kullanılmaktadır. Bilimsel bilgiyi bu bilgilerden ayıran özellikler arasında; bilimsel bilginin kanıta dayalı, nesnel, kümülatif, ispatlanabilir, tekrarlanabilir, ölçülebilir ve sistematik olması sayılabilir. Bilimsel bilginin üretilmesi, diğer bir anlatımla bilimsel araştırma süreci araştırma yöntemleri alanının ve bu alandaki, yeterliliklerin temel içeriğini oluşturmaktadır (Tavşancıl ve diğerleri, 2010).

Bilimsel bilgi üretme işini amaç edinen araştırma süreci, problemlere geçerli ve güvenilir çözümler bulabilmek amacıyla, planlı ve programlı olarak, verilerin toplanması, analizi, yorumlanması ve rapor edilmesi süreci olarak tanımlanmıştır (Mouly, 1963; Best, 1959; akt.Karasar, 2014a). Büyüköztürk (2016) ise benzer şekilde, bilimsel araştırmayı her türlü gerçek ve ilkeyi ortaya koymak için bazı bilgi alanlarında yapılan sistemli ve dayanıklı çalışma ve inceleme olarak tanımlamıştır. Bilimsel araştırmanın sistematik olması adım adım ilerleyen belli aşamaları olan bir süreç olduğu anlamına gelir. Balcı'ya (2010) göre bu aşamalar aşağıdaki gibi sıralanmaktadır:

- Araştırma probleminin teşhisi ve tanımlanması

- Problemle ilgili var olan literatürün taranması

- Araştırma sorularının ifade edilmesi

- Araştırma deseninin geliştirilmesi

- Verilerin toplanması

- Verilerin analizi

- Bulgular ve yorumlanması

Karasar (2014b), bilimin birikimliliğini ve açık seçikliğini sağlamak adına, bu aşamaların sonuna raporlaştırma aşamasını da eklemiştir. Ayrıca bilimsel araştırma için belli düzeyde bir uzmanlığın; yapılan araştırmalardan esinlenebilmek ve faydalanabilmek için de genel bir araştırma kültürünün gerekliliğini savunmuştur. Bahsi geçen bu genel kültürün ve uzmanlığın kazandırılabilmesi için verilen eğitimi ise "araştırma eğitimi" olarak nitelendirmiştir.

Temelde araştırma eğitimi, üniversitelerin işlevi olarak belirtilmektedir. Günay (2004), üniversitenin işlevini; bilgiyi üretmek, aktarmak, sunmak ve yaymak olarak açıklamaktadır. Üniversiteler bu işlevini genelde lisans, özelde yüksek lisans ve doktora programlarıyla yerine getirmektedir. Yüksek lisans düzeyindeki öğrencilerden uzmanlık yapılan bilim alanına özgü bilgi, tutum ve becerilere ek olarak özellikle tez hazırlarken kullanılacak araştırma teknik yeterlilikleri, bilimsel tutum ve davranışları kazanması beklenir (Erdem, 2007). Doktora düzeyindeki öğrencilerden ise bağımsız araştırma yapabilme yeterliliğine sahip olması, özgün bir araştırmanın sonuçlarını ortaya koyması, bilimsel olaylara karşı derin bir bakış açısı ile yorum yapabilme yeteneği kazanması ve araştırma sonuçlarını uygun bir şekilde raporlaması beklenir (Karakütük, 2002). Bu açıdan bakıldığında, yüksek lisans ve doktora programlarındaki öğrencilerin bilimsel araştırma yapabilme yeterliliğinin önemi ve bu programlarda bilimsel araştırmaya yönelik derslerin yer alması gerekliliği ortaya çıkmaktadır.

Erkuş (1999), tarafından yapılan bir çalışmada, Hacettepe, ODTÜ ve Ankara Üniversitesi Eğitim Bilimleri alanında 1990-1996 yılları arasında tamamlanan 93 lisansüstü tez;kullanılan ölçme araçlarının nitelikleri ve yapılan çözümlemelerin uygunluğu açısından incelenmiştir. Incelenen tezlerde geçerliği düşük olan ölçme araçlarının ve uygun olmayan çözümleme tekniklerinin kullanımına ilişkin pek çok sorun bulunmuştur. 
Tavşancıl ve diğerlerinin (2010) ise yaptığı çalışmada, 2000-2008 yılları arasında devlet üniversitelerinin Eğitim Bilimleri Enstitüleri-nde tamamlanmış yüksek lisans tezlerinin "veriler ve toplanması" ile "verilerin çözümlenmesi" alt bölümleri raporlama açısından değerlendirilmiştir. Araştırmadan elde edilen bulgulara göre terimlerin kullanılmasında temel hataların yapıldığı ve farklı kullanımların olduğu ortaya çıkmıştır. Yapılan bu çalışmalar, bilimsel bir araştırmanın doğru bir şekilde yapılandırılıp sunulmasında zorluklar yaşandığını açıkça göstermektedir.

Bir araştırmaya başlamadan önce araştırma önerisinin hazırlanması eksikliklerin ve yaşanabilecek olumsuz durumların görülmesi açısından önemlidir. Yapılan araştırma bir teze yönelik ise Tez Önerisi olarak hazırlanır ve öneriyi kabul edecek kurul önünde sunulur. Kurul tarafından araştırmaya yönelik getirilen eleştiri ve öneriler araştırmanın gelişmesine katkı sağlar. Bu anlamda düşünüldüğünde, araştırma sürecinin en başında gerçekleşen tez önerisinin yazııması aşamasında yaşanan sıkıntılar ve zorlukların düzeyinin belirlenmesi oldukça önemli görülmektedir. Bir araştırma önerisi hazırlanırken, araştırmacıların en çok hangi bölümlerde zorlandıklarının belirlenmesi, eğitim-öğretim sürecinde yer alan ders içerikleri ve bu derslerin işleniş biçimlerinin yeniden yapılandırılması açısından önemli katkılar sağlayacaktır. Nitelikli bir araştırma eğitiminin, beraberinde daha nitelikli yapılan araştırmaların ortaya çıkmasına zemin hazırladığı düşünülürse bu konuda daha fazla araştırmanın yapılmasının gerekliliği ortaya çıkmaktadır. Alanyazın incelendiğinde tez hazırlama sürecinde yaşanan zorluklar konusunda yapılmış araştırmaların sınırlı sayıda olduğu görülmüştür. Bu çalışmalarda ikinci bir dil olarak ingilizce yazılan tezlerde yaşanan zorluklara veya tez yazma sürecinde yer alan kısımlardan sadece birinde yaşanan güçlüklere odaklanılmıştır (Bitchener and Bastürkmen, 2006; Abdusade, 2006; Strauss, 2012; Sadeghi and Khajepasha, 2015). Konuyu bütünü ile ele alan bir ölçekleme çalışmasına ise rastlanmamıştır. Bu amaç doğrultusunda araştırmanın problemi lisansüstü eğitim gören öğrencilerin tez önerisi hazırlarken hangi araştırma bölümlerinde daha çok zorlandıklarını tespit etmektir.

\subsection{Amaç}

Bu çalışmanın amacı lisansüstü öğrencilerinin bir tez önerisi hazırlarken hangi bölümlerde daha çok zorlandıklarını ikili karşılaştırma yöntemi ile ölçeklemektir.

\section{2.Önem}

Sosyal bilimler için araştırma, insan davranışını anlamaya ve bu konuda bilgi birikimini artırmaya çalışan çok yönlü bir etkinlik olarak tanımlanmaktadır (Köklü, Büyüköztürk ve Çokluk, 2006). Tanımından anlaşılacağı üzere sosyal bilimler insan davranışlarını anlama ile ilgilendiğinden ve soyut kavramlarla uğraştığından diğer bilimlere oranla bu alanda araştırma yapmak daha zor olmaktadır. Bu zorluğun en aza indirgenmesi ancak nitelikli bir eğitim programı ile mümkündür. Eğitim öğretim sürecinin iyi yapılanması öğrencilerin eksikliklerinin ve zorluk yaşadığı alanların belirlenmesi ile mümkün olabilir. Bu anlamda araştırmanın eğitimöğretim sürecinde ders içerikleri ve bu derslerin işleniş biçimlerinin yeniden yapılandırılması açısından alana önemli katkı sağlayacağı düşünülmektedir. Araştırma, tez önerisi basamaklarının zorluk düzeylerini psikometrik açıdan ele alması ve bu konuda alanda yapılmış bir çalışma olmaması sebebiyle önemli görülmektedir.

\section{YÖNTEM}

\subsection{Araştırma Modeli}

Bu çalışma, tarama modeli ile desenlenmiştir. Tarama modelleri, geçmişte ya da halen var olan bir durumu var olduğu şekliyle betimlemeyi amaçlayan araştırma yaklaşımlarıdır (Karasar, 
2014). Bu süreçte, araştırmacılara herhangi bir müdahalede bulunulmadığı ve var olan durum olduğu şekli ile ortaya çıkarılmaya çalışıldığı için betimsel araştırma niteliği taşımaktadır.

\section{2.Örneklem}

Çalışma, 2015-2016 Eğitim-öğretim yılında Ankara, Hacettepe ve Mersin Üniversitesi Eğitim Fakültelerinde öğrenim gören; bir ders kapsamında en az bir tez önerisi yazmış olan bilimsel hazırlık öğrencileri, yüksek lisans ve doktora öğrencileri arasından seçilmiş 102 kişi ile gönüllülük esasına dayalı olarak yürütülmüştür. Örneklemin belirlenmesinde uygun örnekleme yöntemi kullanılmıştır. Uygun örnekleme, zaman, para ve iş gücü açısından var olan sınırlıklar sebebiyle örneklemin ulaşılabilir ve uygulama yapılabilir birimlerden seçilmesidir (Büyüköztürk, 2016).

\subsection{Veriler ve Toplanması}

Veri toplama aracının hazırlanması aşamasında, bir tez önerisinde yer alan basamaklar belirlenerek ikili karşılaştırmanın yapılacağı ölçme aracı hazırlanmıştır. Birçok yazar tarafından bir tez önerisi çok küçük farklılıklarla benzer başlıklar altında toplanmaktadır (Day, 2000; Balcı, 2010; Karasar, 2014b; Büyüköztürk, 2016;). Bu çalışmada tez önerisinde yer alan başlıklar aşağıdaki şekilde ele alınmıştır:

- Problem durumu

- Amaç ve alt amaçlar

- Araştırmanın önemi

- Varsayımlar

- Sinırlılıklar

- Araştırma modeli

- Evren ve örneklem

- Veriler ve toplanması

- Verilerin çözümlenmesi

Uzman görüşü doğrultusunda ölçme aracına son şekli verilerek gerekli çoğaltma işlemi yapılmıştır. Uygulamalar bizzat araştırmacılar tarafından yapılmıştır. Uygulama öncesi tez önerisinde yer alan aşamalar konusunda anlam karışıkıklarını önlemek için gerekli açıklamalar yapılmıştır.

\subsection{Verilerin Analizi}

Bu araştırmada Thurstone'un (1927) karşılaştırmalı yargı kanununa dayanan ve uyarıııların, cevaplayıcılara ikişerli olarak verilebileceği her durumda kullanılabilen ikili karşılaştırmalar yoluyla ölçekleme yönteminin V. Hal denklemi kullanılmıştır. Bu yöntem, duyuşsal alandaki birçok özelliğin ölçeklenmesinde kullanılmaktadır (Turgut ve Baykul, 1992). Bu ölçekleme tekniğinde öncelikle katılımcıların ikili olarak yaptıkları karşılaştırmalara ait frekans değerleri belirlenerek frekans matrisi (F) oluşturulur. Frekans matrisindeki değerler, toplam kişi sayısına bölünerek oranlar matrisi $(\mathrm{P})$ oluşturulur. Bir sonraki adımda ise oranlar matrisindeki hücre değerlerine karşılık gelen ( $\mathrm{z}$ ) standart değerleri belirlenerek birim normal sapmalar matrisi ( $\mathrm{Z}$ ) elde edilir. Daha sonra bu değerlerin ortalamaları alınarak ölçek değerleri hesaplanır ve ölçek değerinin başlangıç noktasını belirlemek için en küçük değerin mutlak değeri bütün değerlere eklenerek ölçek değerleri sıralanır.

Ikili karşılaştırma yöntemiyle ölçek değerleri hesaplanırken elde edilen değerler gözlemci yargılarına ve bazı varsayımlara dayandırılır. Varsayımların sağlanıp sağlanmadığının ve gözlemcilerin yargılarında tutarlı olup olmadıklarının kontrol edilmesi için ölçeklemenin iç tutarlığı yoklanır. Bunun için gözlenen oranla teorik oran arasındaki farkın ortalama değerine 
(ortalama hata) bakılır. Ortalama hata değeri küçük ve 0’a yakın ise ise ölçek değerlerinin iç tutarlılığı yüksek ve dolayısıyla güvenilir olduğu, büyük ise ölçek değerlerinin güvenilir olmadığı şeklinde yorumlama yapılır. Başka bir deyişle ortalama hata değeri gözlenen değer ile ampirik değerler arasındaki uyumun bir ölçüsünü verir. Bu uygunluk derecesinin manidar olup olmadığı ki-kare testi ile yoklanır. Guilford (1954), ki-kare testi sonucu elde edilen değerin manidar çıkması durumunda III. Hal denkleminin kullanılmasını önermektedir. Bu teknikte ölçekleme yapılırken aşağıdaki adımlar sırası ile izlenir:

1. Z matrisinin sütun elemanlarının standart kaymaları,

$V_{j}=\frac{1}{K} \cdot \sqrt{K \cdot \sum_{k=1}^{K} z_{k j}^{2}-\left(\sum_{k=1}^{K} z_{k j}\right)^{2}}$ formülünden yararlanılarak hesaplanır.

2. KC sabiti,

$V_{j}=\frac{1}{K} \cdot \sqrt{K \cdot \sum_{k=1}^{K} z_{k j}^{2}-\left(\sum_{k=1}^{K} z_{k j}\right)^{2}}$ formülü ile hesaplanır.

3. $\sigma_{j}=\frac{K \cdot C}{K \cdot V_{j}}-1$ formülü yardımıyla ayırt etme yargılarının standart kaymaları bulunur.

4. Standart kaymaların kareleri alınarak varyans değerleri bulunur. Varyans değerleri ikişer ikişer toplanarak varyans toplamları matrisi elde edilir. Bu matristeki elemanların karekökleri alınır ve varyans toplamları karekökü matrisi elde edilir.

5. Varyans toplamlarının karekökü matrisi ile birim normal sapmalar matrisinin esas köşegeni üzerindeki tüm değerler çarpılarak S matrisi elde edilir.

6. S matrisinde ölçekleme, V. Hal denkleminde bulunan $Z$ matrisindeki gibi sütun ortalamaları alınarak ve en küçük ortalama sıfıra getirilerek tamamlanır.

Bu bilgiler doğrultusunda, araştırma sürecinde çalışmaya katılan her kişiye belirlenen dokuz basamak ikili şekilde sunulmuş ve bu basamakları ikili karşılaştırma yaparak sıralamaları istenmiştir. Araştırmacıların ikili olarak yaptıkları karşılaştırmalara ait frekans değerleri belirlenerek frekans matrisi oluşturulmuştur. Frekans matrisindeki değerler, toplam kişi sayısına bölünerek oranlar matrisi oluşturulmuştur. Bir sonraki adımda ise oranlar matrisindeki hücre değerlerine karşılık gelen standart değerleri belirlenerek birim normal sapmalar matrisi elde edilmiştir. Daha sonra bu değerlerin ortalamaları alınarak ölçek değerleri hesaplanmıştır. Ölçek değerinin başlangıç noktasını belirlemek için en küçük değerin mutlak değeri bütün değerlere eklenerek ölçek değerleri sıralanmıştır.

$\mathrm{Bu}$ işlemlerden sonra Thurstone ikili karşılaştırma kanunun V. Hal denklemi için sahip olduğu varsayımlarını test etmek, gözlemcilerin uyarıcılara verdikleri yargılarda uyum içerisinde olup olmadıklarını tespit etmek için ortalama hata miktarı hesaplanmıştır. Gerekli işlemler yapılarak bu değer 0,011 olarak hesaplanmıştır. Bu hata miktarının anlamlı olup olmadığını test

etmek amacıyla ki kare testi ile iç tutarlılık hesaplanmıştır $(\chi=18,912 ; \mathrm{sd}=28)$. Bulunan bu değer, ilgili serbestlik derecesindeki kritik değeri aşmadığından $(18,912<41,337)$ sonucun anlamlı olmadığına karar verilmiştir. Diğer bir deyişle, V. Hal denkleminin varsayımları karşılandığı için III. Hal denklemine dayalı bir ölçekleme çalışması yapılmasına gerek duyulmamıştır. 


\section{BULGULAR}

Bu çalışmada her bir gözlemciden 9 farklı uyarıcıyı ikişerli olarak karşılaştırması istenmiştir. Bu karşılaştırma sonuçlarına göre, her bir uyarıcıya ilişkin frekans değerleri hesaplanmıştır. Belirlenen frekans değerleri Tablo 1'de verilmiş̧ir. Tablo 1'de,uyarıcılara ilişkin Problem Durumu için (P), Amaç ve Alt amaçlar için (A), Araştırmanın Önemi için (Ö), Varsayımlar için (V), Sınırlılıklar için (S), Araştırma Modeli için (M), Evren ve Örneklem için (E), Veriler ve Toplanması için (VT), Verilerin Çözümlenmesi için (VÇ) kodlaması yapılmıştır.

Tablo1

Frekans Matrisi (F)

\begin{tabular}{cccccccccc}
\hline & $\mathbf{P}$ & $\mathbf{A}$ & $\mathbf{O}$ & $\mathbf{V}$ & $\mathbf{S}$ & $\mathbf{M}$ & $\mathbf{E}$ & $\mathbf{V T}$ & VÇ \\
\hline $\mathbf{P}$ & & 26 & 35 & 22 & 12 & 34 & 25 & 43 & 46 \\
$\mathbf{A}$ & 76 & & 56 & 30 & 22 & 54 & 42 & 57 & 57 \\
$\ddot{0}$ & 67 & 46 & & 27 & 20 & 50 & 35 & 58 & 56 \\
V & 80 & 72 & 75 & & 36 & 67 & 54 & 64 & 68 \\
S & 90 & 80 & 82 & 66 & & 81 & 69 & 81 & 82 \\
M & 68 & 48 & 52 & 35 & 21 & & 36 & 51 & 62 \\
$\mathbf{E}$ & 77 & 60 & 67 & 48 & 33 & 66 & & 67 & 69 \\
VT & 59 & 45 & 44 & 38 & 21 & 51 & 35 & & 65 \\
VÇ & 56 & 45 & 46 & 34 & 20 & 40 & 33 & 37 & \\
\hline
\end{tabular}

Tablo1 'de verilen frekans matrisi, satırdaki uyarıcının sütundaki uyarıcıya göre tercih edilme durumuna göre oluşturulmuştur. Örneğin $P$ uyarıcısını $A$ uyarıcısına tercih eden kişi sayısı 76 iken A uyarıcısını $P$ uyarıcısına tercih eden kişi sayısı 26'dır. Daha açık bir ifade ile 76 kişi problem durumunun yazımının amaç ve alt amaçların yazıımasından daha zor olduğunu düşünürken 26 kişi amaç ve alt amaçların yazılmasının problem durumuna göre daha zor olduğunu düşünmüştür. Bir uyarıcının kendisi ile karşılaştırılma durumu olmadığından frekans matrisinde köşegen üzerinde hiçbir değer yer almamaktadır.

Frekans matrisi bulunduktan sonra oranlar matrisini bulmak için frekans matrisinin her bir hücresindeki değer, ikili karşılaştırmayı yapan toplam kişi sayısı olan 102'ye bölünmüştür. Oranlar matrisine iliş̧in hesaplanan bu değerler Tablo 2'de sunulmuştur.

Tablo 2

Oranlar Matrisi (P)

\begin{tabular}{cccccccccc}
\hline & $\mathbf{P}$ & $\mathbf{A}$ & $\mathbf{0}$ & $\mathbf{V}$ & $\mathbf{S}$ & $\mathbf{M}$ & $\mathbf{E}$ & $\mathbf{V T}$ & VÇ \\
\hline $\mathbf{P}$ & & 0,255 & 0,343 & 0,216 & 0,118 & 0,333 & 0,245 & 0,422 & 0,451 \\
A & 0,745 & & 0,549 & 0,294 & 0,216 & 0,53 & 0,412 & 0,559 & 0,559 \\
O & 0,657 & 0,451 & & 0,265 & 0,196 & 0,49 & 0,343 & 0,569 & 0,549 \\
V & 0,784 & 0,706 & 0,735 & & 0,353 & 0,657 & 0,53 & 0,628 & 0,667 \\
S & 0,882 & 0,784 & 0,804 & 0,647 & & 0,794 & 0,676 & 0,794 & 0,804 \\
M & 0,667 & 0,47 & 0,51 & 0,343 & 0,206 & & 0,353 & 0,5 & 0,608 \\
E & 0,755 & 0,588 & 0,657 & 0,47 & 0,324 & 0,647 & & 0,657 & 0,676 \\
VT & 0,578 & 0,441 & 0,431 & 0,372 & 0,206 & 0,5 & 0,343 & & 0,637 \\
VÇ & 0,549 & 0,441 & 0,451 & 0,333 & 0,196 & 0,392 & 0,324 & 0,363 & \\
\hline
\end{tabular}


Tablo 2 incelendiğinde köşegene göre simetrik olan değerlerin toplamının 1 olduğu görülmektedir. Birim normal sapmalar matrisini elde etmek için öncelikle oranlar matrisinin her bir elemanına karşılık gelen birim normal dağılımının z değerleri belirlenmiştir. Böylece birim normal sapmalar matrisi elde edilmiştir. Birim normal matrisine ait değerler Tablo 3'de gösterilmiştir.

Tablo 3

Birim Normal Sapmalar Matrisi

\begin{tabular}{lllllllllll}
\hline & P & A & Ö & V & S & M & E & VT & VÇ \\
\hline P & & $-0,659$ & $-0,404$ & $-0,786$ & $-1,185$ & $-0,432$ & $-0,69$ & $-0,197$ & $-0,123$ \\
A & 0,659 & & 0,123 & $-0,542$ & $-0,786$ & 0,073 & $-0,222$ & 0,148 & 0,148 \\
Ö & 0,404 & $-0,123$ & & $-0,628$ & $-0,856$ & $-0,025$ & $-0,404$ & 0,174 & 0,123 \\
V & 0,786 & 0,542 & 0,628 & & $-0,377$ & 0,404 & 0,073 & 0,324 & 0,432 \\
S & 1,185 & 0,786 & 0,856 & 0,377 & & 0,82 & 0,457 & 0,82 & 0,856 \\
M & 0,432 & $-0,073$ & 0,025 & $-0,404$ & $-0,82$ & & $-0,377$ & 0 & 0,274 \\
E & 0,69 & 0,222 & 0,404 & $-0,073$ & $-0,457$ & 0,377 & & 0,404 & 0,457 \\
VT & 0,197 & $-0,148$ & $-0,174$ & $-0,324$ & $-0,82$ & 0 & $-0,404$ & & 0,35 \\
VÇ & 0,123 & $-0,148$ & $-0,123$ & $-0,432$ & $-0,856$ & $-0,274$ & $-0,457$ & $-0,35$ & \\
Toplam & 4,476 & 0,399 & 1,335 & $-2,812$ & $-6,157$ & 0,943 & $-2,024$ & 1,323 & 2,517 \\
Ort. Z & 0,497 & 0,044 & 0,148 & $-0,312$ & $-0,684$ & 0,105 & $-0,225$ & 0,147 & 0,28 \\
Sj & 1,181 & 0,728 & 0,832 & 0,372 & 0 & 0,789 & 0,459 & 0,831 & 0,964 \\
\hline
\end{tabular}

Tablo 3 incelendiğinde köşegene göre simetrik olan elemanların birbirinin ters işaretlisi olduğu görülmektedir. Her bir sütuna ait toplam değerlerin gösterilebilmesi için matrisin sonuna bir satır eklenmiştir. Daha sonra bu satırdaki her bir değer uyarıcı sayısı olan 9'a bölünerek ortalama $z$ değerleri elde edilmiştir. Bu değerler toplandığında sonucun sıfıra eşit olduğu görülmektedir. Bir sonraki adımda ise başlangıç noktasını ortalama z satırındaki en küçük değer olan -0,684 sayısına kaydırmak için bu sayının mutlak değeri olan 0,684 sayısı her bir değere eklenmiştir. Böylece her bir özelliğin ölçek değeri belirlenmiştir. Bu ölçek değerleri şekil 1 'deki sayı doğrusu üzerinde gösterilmiştir.

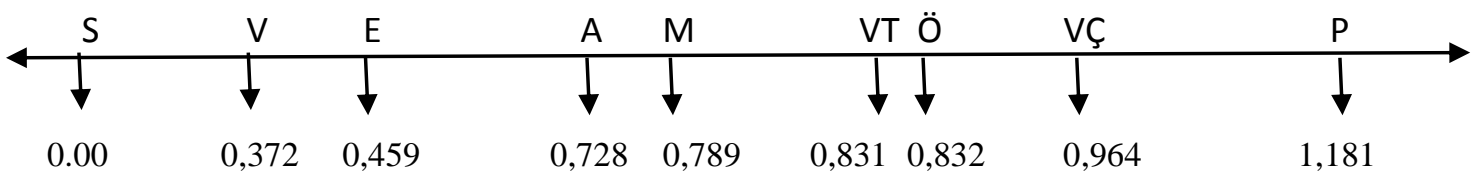

Şekil 1. Özelliklerin sayı doğrusu üzerindeki ölçek değerleri

Tablo 3'ten elde edilen ölçek değerlerine göre tez önerisi bölümlerinin zorluk düzeyleri belirlenmiştir. Tablo 4'te bu bölümler zorluk sırasına göre gösterilmektedir. 
Tablo 4

Tez Basamaklarının Ölçek Değerleri ve Uyarıcı Sıraları

\begin{tabular}{lcc}
\hline Tez Önerisi Basamakları & Ölçek Değerleri & Uyarıcı Sıraları \\
\hline Problem Durumu (P) & 1,181 & 2 \\
Veriler ve Çözümlenmesi (VÇ) & 0,964 & 3 \\
Araştırmanın Önemi (Ö) & 0,832 & 4 \\
Veriler ve Toplanması (VT) & 0,831 & 5 \\
Araştırma Modeli (M) & 0,789 & 6 \\
Amaç ve Alt Amaçlar (A) & 0,728 & 7 \\
Evren ve Örneklem (Ö) & 0,459 & 8 \\
Varsayımlar (V) & 0,372 & 9 \\
Sınırlılıklar (S) & 0 & 5 \\
\hline
\end{tabular}

Tablo 4 incelendiğinde yüksek lisans ve doktora öğrencilerinin tez önerisi yazarken en çok zorluk yaşadığı bölümün problem durumu olduğu görülmektedir. Bunu sırasıyla veriler ve çözümlenmesi, araştırmanın önemi, veriler ve toplanması, araştırma modeli, amaç ve alt amaçlar, evren ve örneklem, varsayımlar ve sınırlılıklar takip etmektedir.

\section{SONUÇ ve ÖNERILER}

Bu çalışmada, yüksek lisans ve doktora öğrencilerinin bir tez önerisi yazarken hangi bölümlerde daha çok zorlandıkları kendi yargılarına dayalı olarak ikili karşılaştırma yöntemi ile ölçeklenmiştir. Araştırma sonucunda öğrencilerin en çok problem durumunu yazarken zorluk yaşadığı ortaya çıkmıştır. Bunu sırasıyla verilerin çözümlenmesi, araştırmanın önemi, veriler ve toplanması, araştırma modeli, amaç ve alt amaçlar, evren ve örneklem, varsayımlar ve sınırlılıklar izlemiştir. Araştırmadan elde edilen bulgular sonucunda problem durumunun öğrencilerin en çok sıkıntı yaşadığı bölüm olarak belirlenmesi öğrencilerin araştırmasının çıkış noktasını, neden gerekli olduğunu, problemi nasıl fark ettiğini açıklamakta zorlandıklarının göstergesidir. Bu durum alan yazın taramasının nasıl yapılacağı ve araştırma probleminin doğasının nasıl raporlaştırılacağı konusundaki bilgi ve beceri eksikliklerden kaynaklanacağı gibi bu bölümün yazılmasında benimsenen farklı yaklaşımların verdiği belirsizliklerden de kaynaklanabilir. Bunun nedeninin nitel bir araştırma yapılarak ortaya çıkarılması önerilmektedir. Hart'a (1998) göre, alanyazın taraması araştırmacıya konu ile ilgili kavramsal çerçeve oluşturmayı sağladığı gibi araştırmanın gerekliliği konusunda araştırmacıyı ikna eder. Ayrıca konunun hangi boyutlarına odaklanılması gerektiği, araştırma probleminin tanımlanmasına ve araştırma yönteminin şekillenmesine yardımcı olur. Bu bağlamda düşünüldüğünde, daha kapsamlı bir alanyazın taramasının ne kadar önemli olduğu ortaya çıkmakla birlikte, ilgili sorunun çözümüne katkı sağlayacağı belirtilebilir.

Yüksek lisans ve doktora öğrencilerine göre verilerin çözümlenmesi zorluk açısından ikinci sırada yer almaktadır. Bu durum öğrencilerin kullandıkları istatiksel teknikleri ve bunları seçme gerekçelerini belirtmekte sıkıntı yaşadıklarının göstergesidir. Bu bulgu, Tavşancıl ve diğerlerinin (2010) bulguları ile paralellik göstermektedir. Tavşancıl ve diğerleri inceledikleri tezlerde, araştırmacıların verilerin çözümlenmesi bölümünde kullanılan veri çözümleme 
teknikleri ve elde edilen istatistiklerin nasıl yorumlandığına ilişkin bilgilere sahip olmadığını ya da yetersiz olduğunu raporlamışlardır. Bu hususta, üniversitelerin yüksek lisans ve doktora programları kapsamında bu konuda verilen derslerin içeriklerinde düzenlemeler yapılması gerektiği belirtilebilir. Özellikle araştırma yöntemleri derslerinin içeriğinde verilerin çözümlenmesi boyutuna daha fazla ağırlık verilmesi ve uygulamaya dayalı etkinliklerin yapılması önerilebilir.

Araştırmadan elde edilen bulgular sonucunda araştırmanın önemi ve veriler ve toplanması bölümlerinin ölçek değerleri birbirine çok yakın bulunmuştur. Araştırmanın öneminin zorluk açısından üçüncü sırada yer alması öğrencilerin araştırmalarının hangi kuramsal ya da pratik sorunun çözümünde ve nasıl kullanılabileceğini açıklamakta güçlük çektiklerini göstermektedir. Bu bulgu öğrencilerin "problem durumu" bölümünü yazarken zorlanmaları ile ilişkili olabilir. Çünkü problem durumunda da problemin doğasının yanı sıra araştırmanın öneminin ve alanda yapacağı katkıların sistematik bir şekilde sunulması gerekir. Elliott and Higgins'e (2012) göre araştırmacıların en çok mücadele ettikleri nokta bir öneriyi akademik gerekçelerle geliştirmektir. Bir araştırma önerisinin gelişmesi ancak daha önce o konu ile ilgili ne bilindiği, ne çalışıldığı hususunda yapılmış geniş bir literatür taraması ile mümkündür ( McGhee, Marland and Atkinson, 2007; Dunne, 2011). Araştırma bulgusu bize araştırma dersi kapsamında literatür taraması boyutuna ağıllık verilmesi gerektiğini göstermektedir.

Araştırmada hangi tür verilerin, hangi kaynaklardan, hangi araçlarla, kimlerle ne zaman toplanacağı tez önerisinin veriler ve toplanması bölümünde açık seçik yazılması gerekir. Ayrıca veri toplamak için anket, test ve benzeri araçlar kullanıımışsa bunların amaçları, nelerden oluştukları nasıl ve kimlerce geliştirildikleri, geçerlik ve güvenirlik kanıtları da bu bölümde yazılması gereken önemli bilgilerdir. Araştırma bulguları öğrencilerin bu bölümde de zorlandıklarının ve dolayısıyla eksikliklerinin olduğunu göstermiştir. Sezgin, Kavgacı ve Kılınç'ın (2011) araştırma bulguları da bu sonuçları destekler niteliktedir. Sezgin ve diğerleri yüksek lisans ve doktora öğrencileri üzerine yaptıkları nitel bir araştırma sonucunda lisansüstü öğrencilerinin özellikle kuram ve uygulama arasında ilişki kurmada, araştırma yöntem ve tekniklerini kullanmada, disiplinler arası ve ülke sorunlarına çözüm getirecek çalışmalar yapmada sıkıntı yaşadıklarını rapor etmiştir. Lisansüstü eğitim programlarının eğitim öğretim süreçlerinde yine bu konudaki eksiklileri giderecek şekilde planlama yapılması önerilmektedir.

Araştırma sonucunda elde edilen dikkat çekici bulgulardan birisi de öğrencilerin tez önerisi yazarken sınırlılıklar ve varsayımlar bölümlerinde daha az zorlandıklarını düşünmeleridir. Bu bulgu öğrencilerin diğer bölümlere göre sınırlılıklar ve varsayımlar bölümlerinde kendilerini yeterli gördüklerini ve daha az bilgi eksiklikleri olduğunu düşündüklerini göstermektedir. Bunun nedeni olarak bu bölümlerin kısa olması ve pek çok çalışmada benzer kalıplaşmış ifadelerin kullanılması gösterilebilir. Bunun yanı sıra öğrencilerin bahsi geçen bölümlerde az zorlandıklarını belirtmeleri bu bölümleri olması gerektiği gibi doğru oluşturdukları şeklinde yorumlanmamalıdır.

Sonuç olarak lisansüstü öğrencilerinin tez önerisi yazarken problem durumu, verilerin çözümlenmesi, araştırmanın önemi, veriler ve toplanması bölümlerinde çok zorlandıkları belirlenmiştir. Zorlanma yaşamalarının sebebi bilgi ya da uygulama eksikliği olabilir. Nitelikli araştırmaların yapılması ancak nitelikli araştırma eğitimi ile mümkün olduğu düşünülürse bu bilgi ya da uygulama eksikliklerini giderici önlemler alınmalıdır.

Bu çalışmada lisansüstü öğrencilerinin bir tez önerisi hazırlarken hangi bölümlerde daha çok zorlandıkları ikili karşılaştırma yöntemi ile ölçeklenmiştir. Ancak elde edilen bulguların olası nedenleri ve gerekçeleri araştırma kapsamı dışında tutulmuştur. Bu durum 
araştırmanın bir sınırlılığı olarak düşünülebilir. Nitel ve daha kapsamlı olarak yürütülecek başka nicel araştırmalar ile elde edilen sonuçların incelenmesi önerilmektedir.

\section{KAYNAKLAR}

Abdusade, M., A. (2006). An analytic study of the postgraduate students' difficulties in writing abstracts in English. Benha University Faculty of Education.1-26

Balcı, A. (2010). Sosyal bilimlerde araştırma; yöntem, teknik ve ilkeler. Ankara: Pegem Akademi.

Best, J. W. (1959). Research in education. Prentice Hill.

Bitchener, J. and Bastürkmen, H. ( 2006). Perceptions of the difficulties of postgraduate L2 thesis students writing the discussion section. Journal of English for Academic Purposes 5(1), 4-18.

Büyüköztürk, Ş. (2016). Bilimsel araştırma yöntemleri. Ankara: Pegem Akademi.

Day, R. (2000). Bilimsel bir makale nasıl yazılır ve yayımlanır? ( Çev. G. Aşkar Altay). Ankara : Tubitak.

Dunne, C. (2011). The place of the literature review in grounded theory research. International Journal of Advanced Nursing, 22(3), 40-44.

Elliott, N. and Higgins, A. (2012). Surviving grounded theory research method in an academic world: proposal writing and theoretical frameworks. The Grounded Theory Review, 11(2), 1-12.

Erdem A. R. (2007). Öğretim üyesinin bilim insanı yetiştirme sorumluluğu ve bu sorumluluğun gerektirdiği mesleki etik. Akademik Dizayn Dergisi, 1(2), 77-81.

Erkuş, A. (1999). Üç üniversitedeki lisansüstü tez çalışmalarının psikometrik açıdan durumu. IV. Ulusal Eğitim Bilimleri Kongresi Bildirileri. Anadolu Üniversitesi, 10-12 Eylül 1997, Eskişehir, s. 75-88.

Günay, D. (2004). Üniversitenin niteliği, akademik özgürlük ve üniversite özerkliği. International Congress on Higher Education, 27-29 Mayıs, İstanbul.

Hart, C. (1998). Doing a literature review. London: Sage Publications.

Karasar, N. (2014a). Bilimsel araştırma yöntemi. Ankara: Nobel Yayın Dağıtım.

Karasar, N. (2014b). Araştırmalarda rapor hazırlama. Ankara: Nobel Yayın Dağıtım.

Köklü, N., Büyüköztürk, Ş., Çoklu, Ö. (2006).Sosyal bilimler için istatistik. Pegem A Yayınları: Ankara.

McGhee, G., Marland, G. R. and Atkinson, J. (2007). Grounded theory research: literature reviewing and reflexivity. Journal of Advanced Nursing, 60(3), 334-342.

Mouly, G. (1963). The science of educational research. D. Van Nostrand.

Sadeghi, K. and Khajepasha, S., A. (2015). Thesis writing challenges for non- native MA students. Research in Post Compulsory Education, 3(20), 357-373.

Sezgin, F, Kavgacı, H ve Kılınç, A. Ç. (2011). Türkiye'de eğitim yönetimi ve teftişi lisansüstü öğrencilerinin özdeğerlendirmeleri. Yüksek Öğretim ve Bilim Dergisi. 1(3), 161-169. 
Strauss, P. (2012). 'The English is not the same' : challenges in thesis writing for second language speakers of English. Teaching in Higher Education 3(17), 283-293.

Tavşancıl, E., Gözen Çıtak, G., Erdem, D., Bağcan Büyükturan,E., Kezer, F., Bilican,S., Yıldııım, Ö., Yalçın, N. (05-07 Mayıs 2010). Eğitim bilimleri enstitülerinde tamamlanmış yüksek lisans tezlerinin ölçme ve değerlendirme terminolojisinin kullanımı ve bir örnekliği açısından incelenmesi. Mersin Üniversitesi Eğitimde ve Psikolojide Ölçme ve Değerlendirme II. Ulusal Kongresi, Merin Üniversitesi, 5-7 Mayıs 2010, Mersin,s. 434-452.

Tavşancıl, E., Çokluk, Ö., Gözen, Çıtak, G., Kezer, F., Yıldırım, Y., Bilican, S., Büyükturan, Bağcan, E., Şekercioğlu, G., Yalçın, N., Erdem, D. ve Özmen, D.,T. (2010). Eğitim bilimleri enstitülerinde tamamlanmış lisansüstü tezlerin incelenmesi (2000-2008). Ankara Üniversitesi Bilimsel Araştırma Projesi.

Turgut, F., M., ve Baykul, Y. (1992). Ölçekleme teknikleri. Ankara: ÖSYM Yayınları. 


\section{SUMMARY}

Science is defined as a job of producing information by using scientific methods. Producing reliable scientific information is based on the researches that was done properly. Preparing a thesis proposal before starting a research is important in the way of realizing deficiencies and negative situations that may arise. When considered in this sense, it is important to determine the degree of troubles and difficulties experienced in the stage of writing thesis proposal which is the beginning of the process. Finding out the difficulties which the graduate students have while writing a thesis proposal will have crucial contribution for restructuring the curriculum and the teaching methods for research methodology courses. The aim of this study is to scale the sections that graduate students have difficulties while writing a thesis proposal with pairwise comparison methods.

This is a survey type of research. The study was conducted with 102 graduate students in Ankara, Hacettepe and Mersin University Faculty of Education in 2015-2016 academic year. Convenient sampling method was used in the study. Data was collected through "Pairwise Comparison Form" which was prepared by the researchers. The data collection form includes pairwise comparison of 9 section of a thesis proposal have. In accordance the expert opinion, the required revisions was done and final form of "Pairwise Comparison Form" was composed. "Pairwise Comparison Form" was administered by the researchers personally. Before the administration, in order to avoid ambiguity, a short reminding about sections in the thesis proposal was done.

The collected data were analyzed using the fifth conditional equation of Thurstone's law of comparative judgement. During the analysis at first frequency matrix $(F)$ was calculated. Ratio matrix $(P)$ was created by dividing the values in frequency matrix to total number of people. In the next step, unit normal deviation matrix (z) was formed by calculating standard $z$ values for each value in ratio matrix. In the end scale values were formed by calculating the mean of those $z$ values. To define the starting point of the scale value, absolute value of smallest scale value was added to all other scale values. Then the average error rate was calculated to test the assumptions of fifth conditional equation. This value was calculated as 0,011 . On the other hand internal consistency was calculated with chi-square test to test

whether this error rate is significant or not $(\chi=18,912 ; s d=28)$. Because this value didn't pass over the critical value it was decided not to do rescaling with the third conditional equation. In other words, the assumptions of fifth conditional equation were met.

Result of the study shows that students have the most difficulties while writing "problem situation"(scale value is 1.181). This situation may be arised because students have lack of skills about how to do literature review or how to report the nature of the research problem. Cause of this situation should be revealed with profound qualitative research.

In the second order graduate students have difficulty while writing "data and analysis" section (scale value is 0.964). This means that the students have difficulties in detecting and calculating statistical techniques which they use for data analysis. So the content of the research methodology courses should focus on data analysis techniques more. Moreover in the statistics courses commonly used data analysis techniques in social sciences should be highlighted.

In the third and the forth order graduate students have difficulty respectively in "importance of the study" and "data collection "sections. Scale values of these section are very close each other (respectively 0.832 and 0.831 ). This shows that students have problem to explain how their research contribute to the theoretical or practical problems. Moreover results shows that students are not good at selecting or developing appropriate data collection tools for their studies.

One of the remarkable findings of this is study is that graduate students have less difficulty in writing "assumption" and "limitations" sections (scale values are respectively 0.371 and 0.00 ). This situations may arise because those sections require shorter explanations compare to other sections. On the other hands in so many researches (thesis) in social science, those sections may have similar explanations such as "it is assumed that participant subjects answered the scale truthful" So students 
may copy and used the explanations in their studies since they are appropriate for many studies in social sciences.

As a result, it is defined that the order of the section while graduate students have more difficulties while writing a thesis proposal are respectively "problem situation"(1.181), "data and analysis"(0.964), "importance of the study" (0.832), "data collection tools" ( 0.831), "research model" (0.789)," aim of the study" (0.728)," Universe and sample "(0.429),"assumptions of the study" (0.372) and "limitation of the study" (0.00). There may be many reason why students have more difficulties while writing specific section. So it is strongly advised to conduct a profound qualitative research to reveal why graduate students have more difficulties in specific sections. 